\title{
AVALIAÇÃO DE MÉTODOS PARA REMOÇÃO DE TOLUENO UTILIZANDO ADSORVENTES ALTERNATIVOS EM MEIOS POROSOS
}

\author{
D. S. BENEDETTI ${ }^{1}$, L. F. DE LIMA ${ }^{1}$, M. G. C. DA SILVA ${ }^{1}$, M. G. A. VIEIRA ${ }^{1}$ \\ ${ }^{1}$ Universidade Estadual de Campinas, Faculdade de Engenharia Química \\ E-mail para contato: deborasotilo@gmail.com
}

\begin{abstract}
RESUMO - $\mathrm{O}$ estudo consiste na análise de métodos e adsorventes em meios porosos na remoção de tolueno presente em efluentes contaminados. As técnicas de adsorção em leito fixo e de barreira permeável foram avaliadas, assim como a viabilidade do uso da lama vermelha e da argila organofílica como adsorventes. Constatou-se, após a realização de testes, a inviabilidade do uso de lama vermelha em leito fixo e, até o presente momento, o uso alternativo da argila organofílica neste mesmo sistema apresentou resultados satisfatórios.
\end{abstract}

\section{INTRODUÇÃO}

A adsorção consiste num processo em que há um elevado grau de remoção de determinados componentes através de uma transferência de massa do tipo sólido-fluido. Esse processo ocorre quando o sólido adsorvente retém a substância (adsorvato) em sua superfície, removendo-as do fluido (GOMIDE, 1980). Por meio da adsorção pode-se remover o poluente do fluido em uma alta porcentagem, e reutilizá-lo.

Um conjunto de substâncias capazes de serem adsorvidas por esta técnica é o chamado BTX, o qual é uma sigla que representa os hidrocarbonetos voláteis e tóxicos presentes em derivados do petróleo: benzeno, tolueno e xileno. Esta toxicidade, mesmo em pequenas concentrações, pode afetar o sistema nervoso central dos seres humanos, o que induz às legislações se tornarem cada vez mais restritivas quanto aos valores limites de BTX no meio ambiente. Com isso, intensifica-se cada vez mais a necessidade em se desenvolver técnicas que promovam a retirada destes poluentes de ambientes contaminados, como o método da adsorção, o qual é cada vez mais empregado para a remoção de compostos BTX por ter se mostrado bastante eficiente (SOUZA, 2013).

Neste estudo definiu-se a análise de dois adsorventes alternativos: lama vermelha e argila organofílica. A lama vermelha é um resíduo da indústria de beneficiamento do alumínio, gerada a partir do refino da bauxita para produção de alumina através do processo Bayer (SOUZA et al., 2011). Argila é uma família de minerais filossilicáticos hidratados, aluminosos de baixa cristalinidade, de partículas muito pequenas. Encontra-se geralmente estável, nas condições termodinâmicas e geoquímicas da superfície terrestre ou de crosta rasa (SANTOS, 1975). 
A técnica de adsorção em sistema de leito fixo consiste na passagem do adsorbato a ser tratado por um leito empacotado numa vazão constante. Parâmetros como a velocidade de passagem do líquido pela coluna, zona de transferência de massa, taxa de adsorção e tempo de residência são determinados de modo a garantir a máxima eficiência do processo (GEANKOPLIS, 1993). Já a técnica de barreira permeável consiste na interceptação perpendicular entre a pluma contaminada e a barreira permeável, levando à adsorção dos contaminantes.

Assim, através de todas as informações mencionadas, foi proposto neste projeto o estudo exploratório da adsorção do composto orgânico volátil, tolueno, em fase líquida por adsorventes alternativos (SOUZA, 2013; SOUZA et al, 2011) através do processo de leito fixo e barreira permeável, na qual a volatização da solução contaminante pode ser, provavelmente, melhor controlada.

\section{ESTUDO DAS TÉCNICAS ANALÍTICAS}

\subsection{Leito Fixo}

\subsubsection{Lama vermelha}

A lama vermelha faz parte do grupo denominado tailings, o qual é constituído por solos detentores da matéria-prima de interesse da indústria. No caso deste tipo específico de solo, soda cáustica é adicionada durante o processo de extração e refino da bauxita (FAHEY et al., 2002; VICK, 1983). Assim, o descarte inapropriado da lama vermelha pode gerar problemas como a contaminação da água tanto presente em superfícies quanto em bacias subterrâneas devido à grande proporção de hidróxido de sódio em sua composição ou até mesmo devido à presença de ferro, alumínio, entre outros compostos; além disso, seu contato com seres vivos e o impacto visual que proporciona têm acarretado problemas diversos.

Esse tailing foi considerado por muito tempo um rejeito inaproveitável para a indústria de alumínio (CHAVES, 1962). Contudo, os problemas ambientais acarretados com sua má disposição e os consequentes custos econômicos envolvidos em seu tratamento têm levado ao desenvolvimento de várias alternativas para seu uso, como adsorvente para remoção ou estabilização de poluentes, uma utilidade muito promissora (SOUZA, 2013).

Para a realização dos experimentos, foi utilizado o equipamento HPLC (High Performance Liquid Chromatography) e o fornecimento da lama vermelha usada para os testes deu-se pela empresa Alunorte S.A., situada em Barcarena, PA, com $\mathrm{pH}=13$. Foram utilizadas peneiras de mesh 80, 100 e 150, para a obtenção da faixa de abertura desejada. Após o peneiramento e obtenção da granulometria adequada, a lama vermelha foi seca em estufa a $105^{\circ} \mathrm{C}$, por $12 \mathrm{~h}$ e, posteriormente, passou por um tratamento térmico de calcinação em mufla a $550{ }^{\circ} \mathrm{C}$ por $4 \mathrm{~h}$ para que ocorresse o aumento de sua resistência mecânica e estabilidade.

O leito fixo era preenchido com lama vermelha e, inicialmente, era passado por dentro dela apenas água para visualizar seu comportamento. Logo nos primeiros ensaios verificou-se 
que a lama estava sendo carregada pela solução, o que levou a testes com diferentes vazões para tentar sanar o problema, não obtendo, entretanto, sucesso. A segunda tentativa de corrigir este problema foi o uso da lama com granulometria superior: peneirou-se o material em peneiras com maior abertura e seguiram-se as demais etapas do preparo do adsorvente. Novamente, não foi possível evitar que a lama fosse levada pelo fluxo do fluido escoante.

Diante deste panorama, foi verificada a real impossibilidade de aplicar lama vermelha em leito fixo, pois as partículas são todas carregadas. Isto levou à busca por novas técnicas e novos materiais.

\subsubsection{Argila organofílica}

Argilas normalmente são incompatíveis com meios hidrofóbicos, deste modo, para que sua compatibilidade com o meio orgânico seja elevada, as argilas são tratadas com compostos orgânicos adequados a fim de que uma parte da cadeia destes compostos tenha afinidade com a superfície do argilomineral, aprimorando um conjunto de propriedades do compósito formulado (SILVA e FERREIRA, 2008). A mudança do caráter hidrofílico para hidrofóbico da argila, segundo muitos pesquisadores, levou à otimização na adsorção de compostos orgânicos (STOFELA, 2014).

Neste trabalho foi também selecionada a Argila Organofílica comercial Spectrogel tipo C (cedida pela empresa SpectroChem) como um possível substituto à lama vermelha nos testes em leito fixo. Este material foi utilizado no trabalho de Stofela (2014) em sistema estático de banho finito, tendo sua boa afinidade com efluentes contaminados com BTX já comprovada em sistema estático.

Para o preparo do adsorvente foi realizado o peneiramento com peneiras do tipo Tyler, de mesh 24 e 28 , correspondente a uma granulometria média de 0,655 mm (STOFELA, 2014). Foi feito o teste em coluna de leito fixo e o experimento foi realizado em duplicata. O primeiro foi realizado a uma vazão de $5 \mathrm{~mL} \cdot \mathrm{min}^{-1}$ a partir de uma solução de tolueno de 63,90 ppm, mantida em um banho de gelo e vedada com Parafilm ${ }^{\circledR}$ para bloquear os efeitos de volatilização característicos do tolueno. O segundo ensaio foi realizado a uma vazão de 2,5 mL.min ${ }^{-1}$ a partir de uma solução de tolueno de 89,11 ppm, vedada com Parafilm ${ }^{\circledR}$ e mantida a uma temperatura média controlada de $6,0{ }^{\circ} \mathrm{C}$ empregando-se um banho de gelo. Um adicional do primeiro para o segundo teste é que no último a concentração da solução que alimenta o leito (solução-mãe) foi medida periodicamente, bem como a sua temperatura. Os dados obtidos com os testes exploratórios estão expostos na Tabela 1 e as curvas de ruptura ilustradas na Figura 1, bem como a quantidade total removida (qt), obtida pela Equação 1.

$$
q t=\frac{C o \cdot Q}{m} \cdot \int_{0}^{\infty}\left(1-\frac{C}{C o}\right) \cdot d t
$$

Sendo: $\mathrm{C}_{0}$ : concentração inicial do tolueno $\left(\mathrm{mmol}^{\mathrm{L}} \mathrm{L}^{-1}\right)$, Q: vazão do sistema $\left(\mathrm{mL} \cdot \mathrm{min}^{-1}\right), \mathrm{m}$ : massa total de adsorvente na coluna (g), C: concentração do tolueno no instante $\mathrm{t}\left(\mathrm{mmol} . \mathrm{L}^{-1}\right), \mathrm{t}$ é o tempo de ensaio de adsorção (min).

Tabela 1 - Dados das curvas de ruptura. 
XI Congresso Brasileiro de Engenharia Química em Iniciação Científica Unicamp - Campinas - SP 19 a 22 de julho de 2015

\begin{tabular}{|c|c|c|c|c|c|}
\hline $\begin{array}{c}\text { Tempo } \\
\text { (min) }\end{array}$ & $\mathrm{C} / \mathrm{Co}$ & $\begin{array}{l}\text { Remoção } \\
\text { (\%) }\end{array}$ & $\begin{array}{c}\text { Tempo } \\
\text { (min) }\end{array}$ & $\mathrm{C} / \mathrm{Co}$ & Remoção (\%) \\
\hline 0 & 0,210 & 78,937 & 0 & 0 & 100 \\
\hline 10 & 0,212 & 78,755 & 10 & 0 & 100 \\
\hline 20 & 0,233 & 76,607 & 20 & 0,115 & 88,466 \\
\hline 30 & 0,253 & 74,607 & 30 & 0,126 & 87,348 \\
\hline 40 & 0,260 & 73,959 & 40 & 0,130 & 86,961 \\
\hline 50 & 0,265 & 73,486 & 50 & 0,132 & 86,703 \\
\hline 60 & 0,270 & 72,964 & 60 & 0,138 & 86,137 \\
\hline 80 & 0,272 & 72,790 & 80 & 0,162 & 83,791 \\
\hline 100 & 0,255 & 74,405 & 100 & 0,230 & 76,913 \\
\hline 120 & 0,294 & 70,514 & 120 & 0,248 & 75,151 \\
\hline 150 & 0,321 & 67,808 & 160 & 0,276 & 72,343 \\
\hline 180 & 0,329 & 67,052 & 180 & 0,242 & 75,727 \\
\hline 210 & 0,313 & 68,665 & 210 & 0,241 & 75,880 \\
\hline 240 & 0,311 & 68,805 & 240 & 0,294 & 70,568 \\
\hline 300 & 0,287 & 71,247 & 300 & 0,254 & 74,508 \\
\hline- & - & - & 360 & 0,305 & 69,460 \\
\hline- & - & - & 420 & 0,275 & 72,437 \\
\hline \multicolumn{3}{|c|}{$q t_{\text {ensaio } 1}=152,903 \mathrm{mmol} / \mathrm{g}$ de adsorvente } & \multicolumn{3}{|c|}{$q t_{\text {ensaio } 2}=121,668 \mathrm{mmol} / \mathrm{g}$ de adsorvente } \\
\hline
\end{tabular}

Figura 1 - Curva de ruptura para (a) $1^{\circ}$ Ensaio; (b) $2^{\circ}$ Ensaio.

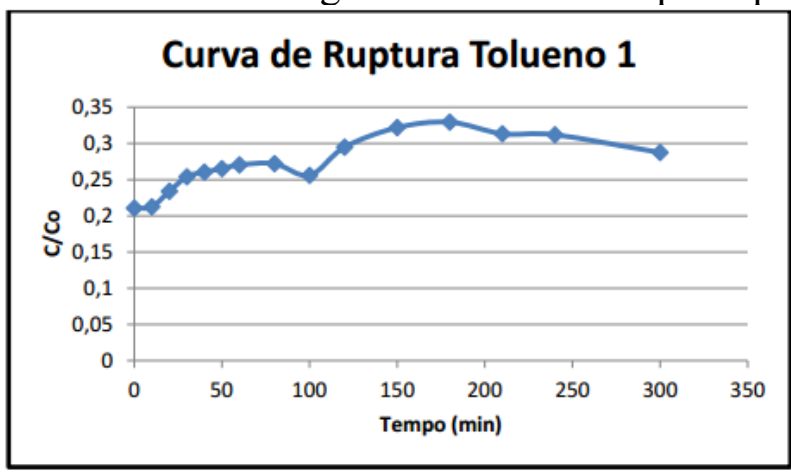

(a)

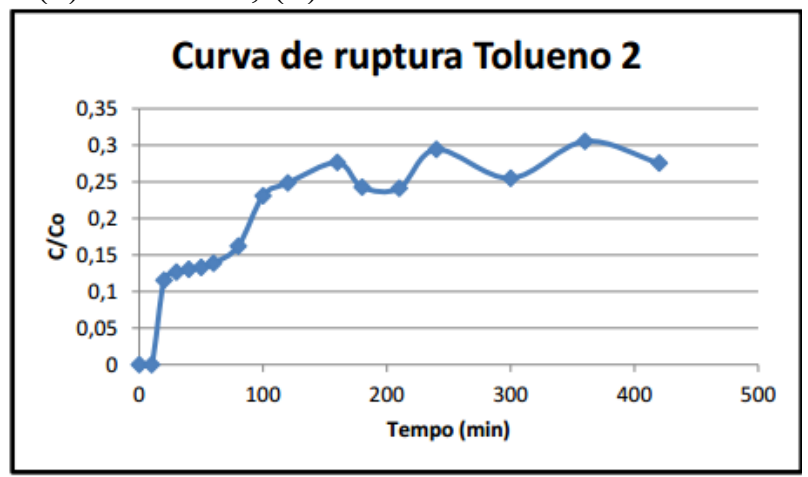

(b)

Como mostrado com os testes preliminares, a aplicação de argila organofílica Spectrogel em leito é uma técnica possível. Entretanto, é preciso um estudo mais profundo para que o leito apresente um comportamento mais próximo do ideal, ou seja, apresente um maior valor de tempo de remoção útil e uma Zona de Transferência de Massa estreita, com baixa resistência difusional. Um maior controle na manutenção da concentração da solução mãe é necessário, visto que o tolueno é extremamente volátil.

\subsection{Barreira Permeável}


Outro procedimento para aplicação de adsorção é a barreira permeável, pois na literatura encontram-se diversos relatos sobre a eficácia da técnica para tratamento de áreas contaminadas com BTX (CRESCÊNCIO JÚNIOR, 2008). O processo consiste na interceptação perpendicular entre a pluma contaminada e a barreira permeável, levando à adsorção dos contaminantes. Surgiu casualmente numa universidade canadense, onde foi observado que poços revestidos com ferro degradavam contaminantes constituídos por compostos orgânicos clorados presentes na água (GILLHAM \& O'HANNESIN, 1994). Scherer et al. (2000) afirmam que a adsorção tem recebido mais atenção como um mecanismo viável para remoção de contaminantes em barreiras permeáveis reativas já que apresentam a vantagem de não inserir compostos químicos no fluxo em tratamento.

Entre as formas de configuração mais comuns das barreiras permeáveis, que são as de paredes contínuas e as de funnel-and-gate (funil-e-portão) (STARR \& CHERRY, 1994). Aparenta-se ser mais interessante a aplicação das de paredes contínuas, pela vantagem de minimizar a velocidade de fluxo e, consequentemente, maximizar o contato entre as partículas contaminantes e o meio adsorvente, o que é mais propício em escala laboratorial. A prática dos testes em laboratório consiste da montagem do processo em uma caixa de vidro, dispondo as seguintes camadas: pedrisco, areia, material adsorvente e solo, respectivamente, tendo suas dimensões evidenciadas na Figura 2 (MANENTI et al., 2007).

Uma manta geotêxtil é utilizada com a intenção de impedir a dispersão das camadas. Acima desta, coloca-se um recipiente com solução contaminante, devidamente vedado e termicamente controlado a fim de se evitar a volatilização. Após a montagem do processo, simula-se um vazamento no recipiente a uma vazão de aproximadamente $600 \mathrm{~mL} / \mathrm{h}$, retirando-se amostras de $30 \mathrm{~mL}$ num intervalo de 0, 12, 24, 48, 72 e 96 horas (MANENTI et al., 2007). As análises de concentração são realizadas no HPLC, nas mesmas condições descritas para os testes em leito.

Figura 2 - Desenho esquemático do sistema de BRP em escala laboratorial.

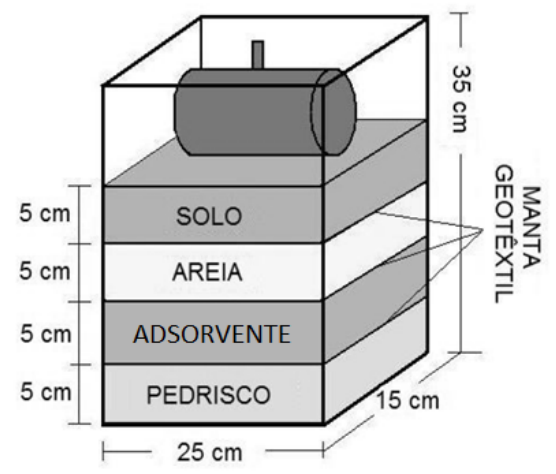

Assim como a aplicação de argila organofílica em leito fixo, a técnica de barreira permeável apresenta, inicialmente, ser outra possível opção, pois a volatilização da solução contaminante pode ser, provavelmente, melhor controlada. Para aplicação de lama vermelha, entretanto, como as partículas são facilmente carregadas, a técnica não parece viável.

\section{CONCLUSÃO}


A inviabilidade da elaboração de um sistema de adsorção em leito fixo utilizando a lama vermelha como adsorvente foi constatada a partir dos experimentos realizados, assim como a possibilidade da realização do sistema mencionado utilizando argila organofílica como alternativa. O método da barreira permeável, sobre o qual foi realizada uma análise teórica, será reproduzido em escala laboratorial para que sua viabilidade ou não possa ser constatada. Além disso, será estudada a otimização dos processos viáveis.

\section{REFERENCIAS}

CHAVES, A. G. F. A lama vermelha e sua eliminação da fábrica de alumina, In: $2^{\circ}$ semana de estudos. Alumínio e Zinco. Sociedade de Intercâmbio Cultural e Estudos Geológicos dos Alunos da Escola de Minas de Ouro Preto, n. 2, Ouro Preto, Minas Gerais, 1962.

CRESCÊNCIO JÚNIOR, F. Estudo de Turfas em Laboratório como Barreira Reativa na Remediação de Aqǘ́feros. Rio de Janeiro. 2008.

FAHEY, M., NEWSON, T. A. e FUJIYASU, Y. Engineering with tailings. Environmental Geotechnics, v. 2, Balkema, pp. 947-973, Rio de Janeiro/RJ. 2002.

GEANKOPLIS, C. J. Transport processes and unit operations. New York, $4^{\mathrm{a}}$ ed., 1993.

GILLHAM, G. P. \& O'HANNESIN. Enhanced Degradation of Halogenated Aliphatics by zero-valent Iron. Ground Water,v.32,n.1, pp.958-987. 1994.

GOMIDE, R. Operações Unitárias. Edição do autor, São Paulo, 1980.

MANENTI, D. R. et al. Aplicação de Barreira Reativa Permeável na Redução da Contaminação por Vazamentos em Tanques De Combustíveis. Revista Tecnológica. v. 16, p. 45-51, 2007.

SANTOS, P.S. Tecnologia de argilas aplicada às argilas brasileiras. Edgard Blucher. 1975.

SCHERER, M. M.; RICHTER, S.; VALENTINE, R. L. \& ALVAREZ, P. J. J. Chemistry and Microbiology of Permeable Reactive barriers for in situ groundwater cleanup-Critical Reviews in Microbiology. 2000.

SILVA, A. R. V.; FERREIRA, H. C. Esmectitas organofílicas: conceitos, estruturas, propriedades, síntese, usos industriais e produtores/fornecedores nacionais e internacionais. Revista Eletrônica de Materiais e Processos. v. 3, p. 1-11, 2008.

SOUZA, R. S.; EL DIDI, H. S.; DA SILVA, M. G. C. Removal of benzene from aqueous solution using raw red mud. Chemical Engineering Transactions, 24, 1225-1230. 2011.

SOUZA, R. S. Avaliação da Lama Vermelha para Aplicação em Barreiras Reativas Permeáveis no Tratamento de Vazamentos de BTEX. UNICAMP, Campinas-SP. 2013.

STARR, R. C. \& J. A. CHERRY. In Situ Remediation of contaminated Groundwater: the funnel-and-gate System. Groundwater, v. 32, n. 3, pp. 465-476. 1994

STOFELA, S. K. F. Remoção de Compostos BTX em Argila Organofílica por Adsorção em Fase Líquida. FEQ/UNICAMP, Campinas-SP (Tese de mestrado). 2014.

VICK, S. G. Planning, Design and Analysis of Tailings Dams, United States of America. 1983.

\section{AGRADECIMENTO}

Os autores agradecem ao CNPq pelo apoio financeiro. 